\title{
Flash Lamp Annealing Method for Improving Adhesion Strength on the Dielectric Material and Reducing Substrate Warpage
}

\author{
Jong-Young Park ${ }^{1,2,3}$, Byeong-Jae Choi ${ }^{1,2}$, Young-Jae Kim ${ }^{2,3}$, Hideo Honma ${ }^{1,2}$ and Joo-Hyong Noh ${ }^{1,2}$ \\ 1. Department of Materials and Surface Engineering, Graduate School of Engineering, Kanto Gakuin University, 1162-2 Ogikubo, \\ Odawara 250-0042, Japan \\ 2. Materials and Surface Engineering Research Institute, Kanto Gakuin University, 1162-2 Ogikubo, Odawara 250-0042, Japan \\ 3. Daeduck Electronics Co. Ltd., 335, Somanggongwon-ro, Siheung-si, Gyeonggi-do 15106, Korea
}

\begin{abstract}
Today's electronic devices have required higher performance properties for 5G and artificial intelligence (AI). High-performance system on chip (SOC), graphic processing unit (GPU), and central processing unit (CPU) requires advanced packages to meet demands for performance, size, and high-speed transmission. To respond to these demands, integration approaches such as 3D IC chip stacking, package on package (PoP), 2.5D interposer integration, system-in-package (SiP), and fan-out packaging technologies have emerged $[6,8,11,12]$. Therefore, the package substrate for high-performance device will require low transmission loss and the small package warpage. Low loss materials have limitation of seed layer formation with electroless Cu plating. Also, heat treatment has major impact on substrate warpage in order for growth of plated $\mathrm{Cu}$ metal and curing for epoxy mold compound (EMC) process. In this paper, we believe it is possible to create a seed layer on the low-loss material by combining electroless $\mathrm{Cu}$ plating and flash lamp annealing (FLA) method instead of sputtering process. In terms of warpage control and metal growth, the flash lamp treatment, not the conventional convection or hot plate type heat treatment, could improve electro-migration between metal line and line through improving large number of (111) slip directions. In addition, flash lamp not only provides alternative to conventional heat treatment process but also significantly reduces substrate warpage. Through result of this study, by using FLA method for advanced package, it is possible to provide solutions in improving adhesion strength between dielectric materials and deposited metal film, and to reduce the warpage of the substrate.
\end{abstract}

Key words: High performance device, advanced package, low-loss dielectric material, warpage control, FLA.

\section{Introduction}

The growth of semiconductor applications in mobile, gaming, automotive, and high-performance computing has been dramatic in recent years. Advanced packaging provides potential solution for systems with better performance and more functions at a smaller form factor, lower cost, lower power consumption, and a shorter time to market $[1,13]$. Emerging of advanced package, low-loss dielectric material has been adopted for loss transmission at the data server and related 5G. Furthermore, small

Corresponding author: Jong-Young Park, resercher, research fields: materail and surface. warpage has become more important factor that reduces to failure when assembling both substrate and wafer caused in increasing $\mathrm{I} / \mathrm{O}$ count tremendously. As of this reason, usually low coefficient of thermal expansion (CTE) is known to reduce package warpage, so the substrate material with low CTE is also required [7]. And the need to improve process condition is also very important; it is because substrate was affected by several heat-treatments such as growth of $\mathrm{Cu}$ metal and epoxy mold compound (EMC) curing. In this paper, flash lamp annealing (FLA) method was used for improvement of adhesion strength between low-loss dielectric material and deposited metal film as well as alternative 
heat-treatment. FLA used in system continuously irradiates $\mathrm{Xe}$ flash discharge with relatively low irradiance $\left(<1 \mathrm{~J} \cdot \mathrm{cm}^{-2}\right)$ and frequency of $3 \mathrm{~Hz}$ by the devising of a particular circuit design of the system [5, 9].

\section{Experimental Setup}

\subsection{Adhesive Strength of Low-Loss Dielectric Material for Seed Layer Formation}

Relatively low resistivity metal and low-K materials were adopted to reduce resistive-capacitive (RC) delay in semiconductor field. Package substrate in packaging field has also increasingly required not only low Dk/Df dielectric material but also considered skin effect treatment as effort to reduce signal loss. For this reason, the sample used low Dk/Df dielectric materials as consisting of the value of 3.0 dielectric constant and 0.003 dissipation factor (Ajinomoto GL series). GL series need to pre-cure with $170{ }^{\circ} \mathrm{C}$ to 30 minutes for physical properties as thermal-set dielectric material. After, the sample was irradiated by ultra violet in order to accelerate Pd absorption on the dielectric material through surface modification. The equipment used for surface modification was UV irradiation equipment fitted with low pressure $\mathrm{Hg}$ lamp source. The low pressure $\mathrm{Hg}$ lamp has wavelengths of $184.9 \mathrm{~nm}\left(11.5 \mathrm{~mW} / \mathrm{cm}^{2}\right)$ and 253.7 $\mathrm{nm}\left(88.44 \mathrm{~mW} / \mathrm{cm}^{2}\right) \quad[2,3]$. Modified surface modification sample was conducted on electroless $\mathrm{Cu}$ plating included in amount of 7 to $8 \mathrm{wt} \%$ Nickel in solutions. Table 1 shows process of experiment. After, heat treatments as conventional heat-treatment and FLA treatment were conducted that not only remove residual stress when deposited in electroless plating but also improve adhesion strength between modified layer and deposited metal film. Table 2 shows condition of heat-treatment and FLA treatment. The flash lamp has 200 to $1,000 \mathrm{~nm}$ pulse wavelength and 0.2 to $1 \mathrm{msec}$ pulse width. Electrolytic plating with the level of $20 \mu \mathrm{m}$ was processed after both heat-treatment and FLA for electroless annealing. In order to measure the adhesion strength between the modified dielectric material and deposited metal, the deposited metal film with $10 \mathrm{~mm}$ width was peeled vertically at the speed of $50 \mathrm{~mm} / \mathrm{min}$ from the modified dielectric material surface using an Instron tester (Shimadzu EZ-test). The sample was observed with cross section and field emission scanning electron microscopes (FE-SEM) that showed how deeply the metal deposited into the modified layer.

\subsection{Growth of Cu Metal Line}

Copper clad laminate (CCL) plate was treated for electrolytic plating with 2 ampere square for density (ASD) to 20 minutes for obtaining up to $10 \mu \mathrm{m}$ thickness.

Table 1 Process of adhesion strength on the dielectric material.

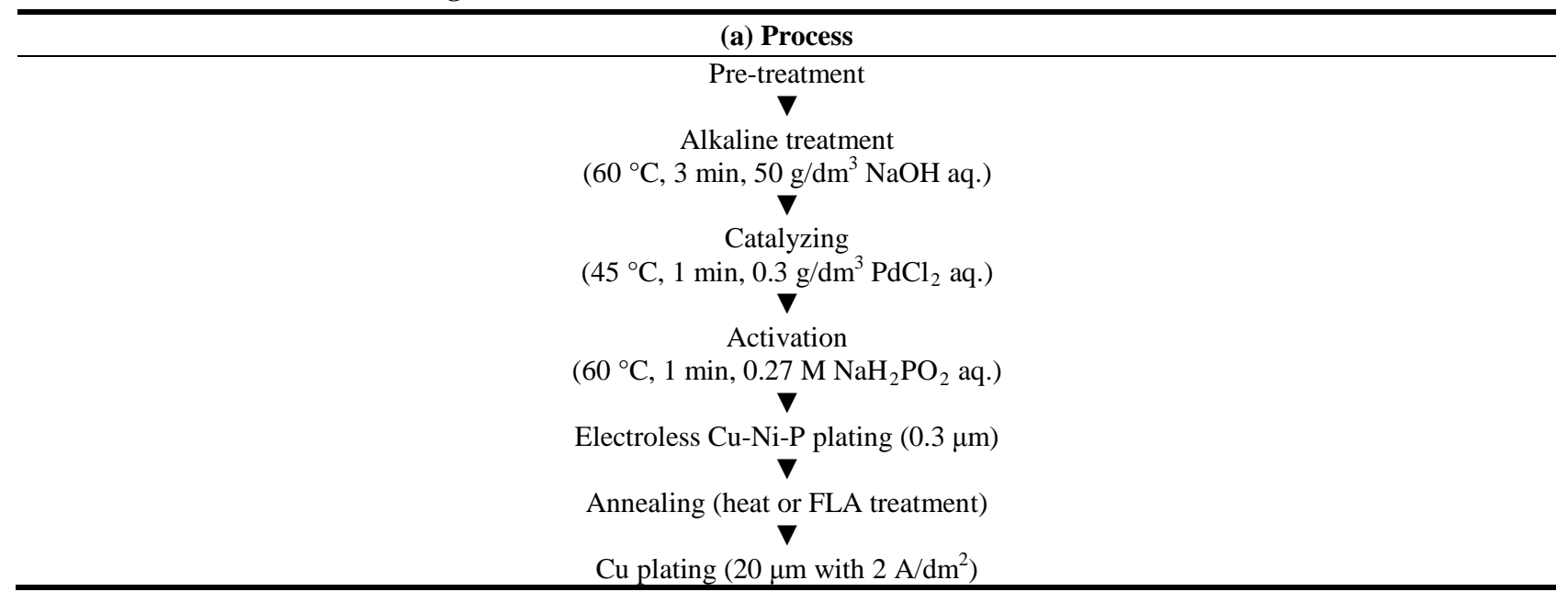


Table 2 Condition of heat-treatment and FLA treatment.

\begin{tabular}{llll}
\hline Convection type heat-treatment & FLA (flash lamp annealing) & \\
\hline Temperature $\left({ }^{\circ} \mathrm{C}\right)$ & 150 to 200 & Power (V) & 700 to 1,300 \\
Time (min) & 30 to 60 & Time (sec) & 50 to 200 \\
& & Pulse wavelength (nm) & 200 to 1,000 \\
& & Pulse width (msec) & 0.2 to 1 \\
& Luminous cycle (count/sec) & 2.5 \\
\hline
\end{tabular}

The sample was treated with heat-treatment and FLA treatment in order for metal growth and to obtain low resistivity. As regarding of each treatment, the samples were conducted $150{ }^{\circ} \mathrm{C}$ to $60 \mathrm{~min}, 800 \mathrm{~V}$ to $200 \mathrm{sec}, 100 \mathrm{~V}$ to $200 \mathrm{sec}$ and $1,200 \mathrm{~V}$ to $200 \mathrm{sec}$. The non-destructive inspection and destructive inspection were conducted to observe grain size of $\mathrm{Cu}$ according to each treatment. As method of non-destructive inspection, we observed surface morphology by FE-SEM which etched surface in $10 \mathrm{wt} \% \mathrm{H}_{2} \mathrm{SO}_{4}-7 \mathrm{wt} \%$ $\mathrm{H}_{2} \mathrm{O}_{2}$ solutions. X-ray diffraction (XRD) analyses were implemented to observe change of slip direction. To observe grain size of $\mathrm{Cu}$ regarding vertical directions in $10 \mu \mathrm{m}$ plating thickness, the sample was polished with cross polishing (CP) equipment with the speed of $3 \mu \mathrm{m}$ per hour and measured by FE-SEM.

\subsection{EMC Curing with Small Warpage}

The specimens were prepared film by type mold material (LE-T series in Ajinotomo film). Sample size was cut into $50 \mathrm{~mm} \times 50 \mathrm{~mm}$ from unprocessed film base in molding material with $100 \mu \mathrm{m}$ thickness. The sample was treated by two types of heat treatment which are both conventional convection with $150{ }^{\circ} \mathrm{C}$ to $60 \mathrm{~min}$ and FLA with $800 \mathrm{~V}$ to $200 \mathrm{sec}, 1,000 \mathrm{~V}$ to $200 \mathrm{sec}$ and $1,300 \mathrm{~V}$ to $200 \mathrm{sec}$. Each treated sample was measured by method of measuring up amount of edge warp from bottom, in comparison with untreated sample. We measured curing by differential scanning calorimetry (DSC) in order to confirm whether or not post-cured after each treatment. Post-cure of EMC in thermal-set material is fairly important. If insufficient, EMC would have electrical problem which is from outer shock or water penetration.

\section{Experimental Results}

\subsection{Adhesive Strength of Low-Loss Dielectric Material for Seed Layer Formation}

The sample used in this study, usually recommended sputtering technology without electroless plating, it is because, the sample including very strong $\mathrm{C}-\mathrm{C}$ bonding could not expect for surface modification through permanganate, plasma and UV irradiation. In this paper, the sample was conducted on electroless $\mathrm{Cu}$ plating on the modified surface with UV irradiation. And it was observed to how deep diffusion layer deposited into metal in the modified layer after each heat treatment. Fig. 1 shows thickness of diffusion layer result according to convection heat treatment and FLA treatment.

According to Eq. (1), diffusion coefficient was increased as temperature in increased, that is, deposited metal was more deeply into modified layer in dielectric material. As this reason, we can expect improvement of adhesion strength.

$$
D=D_{0} \exp \left(\frac{-E a}{k T}\right)
$$

where $D$ : diffusion coefficient $\left(\mathrm{m}^{2} / \mathrm{s}\right), \quad D_{0}$ : pre-expontial $\left(\mathrm{m}^{2} / \mathrm{s}\right), E_{\mathrm{a}}$ : activation energy $(\mathrm{J} / \mathrm{mol}), T$ : absolute temperature (K).

Especially, the case of 1,300 V-200 sec condition in the FLA treatment showed formed thicker diffusion layer compared to other conditions. The lamp energy can be explained in Eq. (2).

$$
W=\frac{1}{2} C V^{2}
$$

where $W$ : energy (work), $C$ : capacitance, $\mathrm{V}$ : voltage.

Used flash lamp has 200 to $1,000 \mathrm{~nm}$ as pulse 


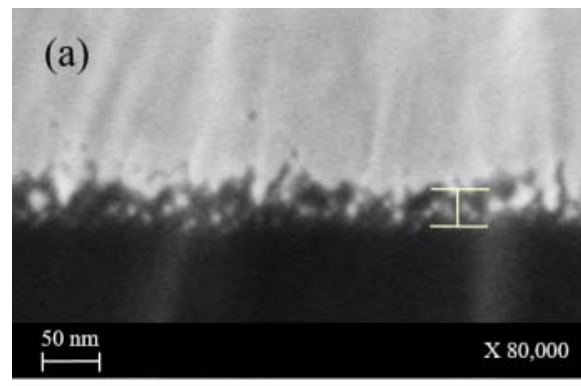

(c)

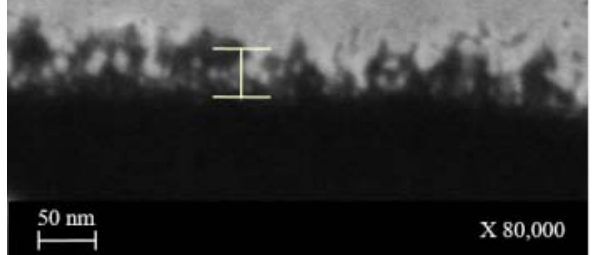

(b)

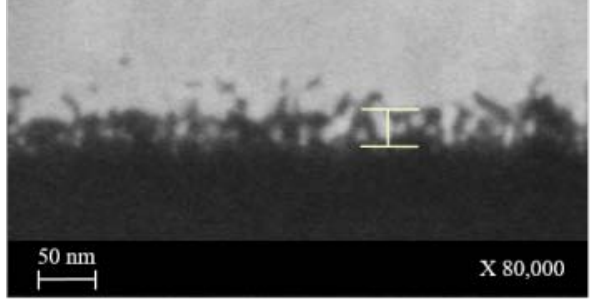

(d)

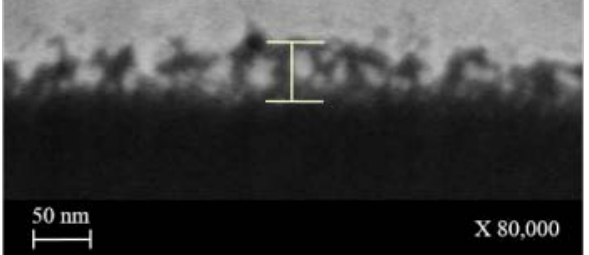

Fig. 1 Thickness of diffusion layer according to each treatment: (a) untreated, (b) $150{ }^{\circ} \mathrm{C}-30 \mathrm{~min},(\mathrm{c})$ 1,000 V-200 sec and (d) 1,300 V-200 sec.

wavelength and 0.2 to 1 msec as pulse width, especially lamp can be gain higher peak power through pulse width adjusting in the out-put energy. As FLA effect, Xe lamp used has 200 to $1,000 \mathrm{~nm}$ pulse wavelength through 1 count of luminescence, also could have sufficient power with adjusting pulse width and continuous multi pulse shot. Particularly, pulse width is adjusted to expect high peak power and multi-pulse shot continuously and to help accumulate energy irradiated surface in sample before energy dissipation. As shown in Fig. 2, the sample of treated $1,300 \mathrm{~V}$ to $200 \mathrm{sec}$ in FLA treatment has highest adhesive strength as the level of $0.45 \mathrm{kgf} / \mathrm{cm}$. On the other hand, convection heat treatment occurred at metal blist on the surface and shows very low adhesive strength as $0.05 \mathrm{kgf} / \mathrm{cm}$.

\subsection{Growth of Cu Metal Line}

Plated metal line including low resistivity, electromigration and resistiveness for formation of hillock was required to improve RC delay. Representatively, $\mathrm{Cu}$ was used in advanced metallization metal because it has relatively low resistivity and superior electromigration reliability. Electromigration could explain that the phenomenon moves around the atom of forming metal interconnection by flow current. Especially, migration influence has become more important factor in case of closer between metal line and metal line $[4,10]$. Consequently, it is imperative to reduce electro-migration problem for more fine pitch metal lines. In the view of the plated metal line from electrolytic plating, $\mathrm{Cu}$ metal line should include low stress, relatively cluster grain size and ship direction of (111). Eq. (3) shows relation between mirco-structure of metal line and electromigration.

$$
M T T F \propto G=\frac{S}{\sigma^{2}} \log \left(\frac{I_{111}}{I_{200}}\right) 3
$$

MTTF: mean time failure;

$G$ : geometrical factor;

$S$ : average grain size;

$\sigma$ : standard deviation of grain size;

I: X-ray diffraction peak intensity.

According to above equation, heat treatment was optimized when geometrical factor $G$ is the maximum. The mean of increased (111) slip direction is as same as to improve electromigration resistance, because (111) slip directions include low grain boundary diffusion. Probability of breakage will be reduced by electromigration in which most of electromigration is 


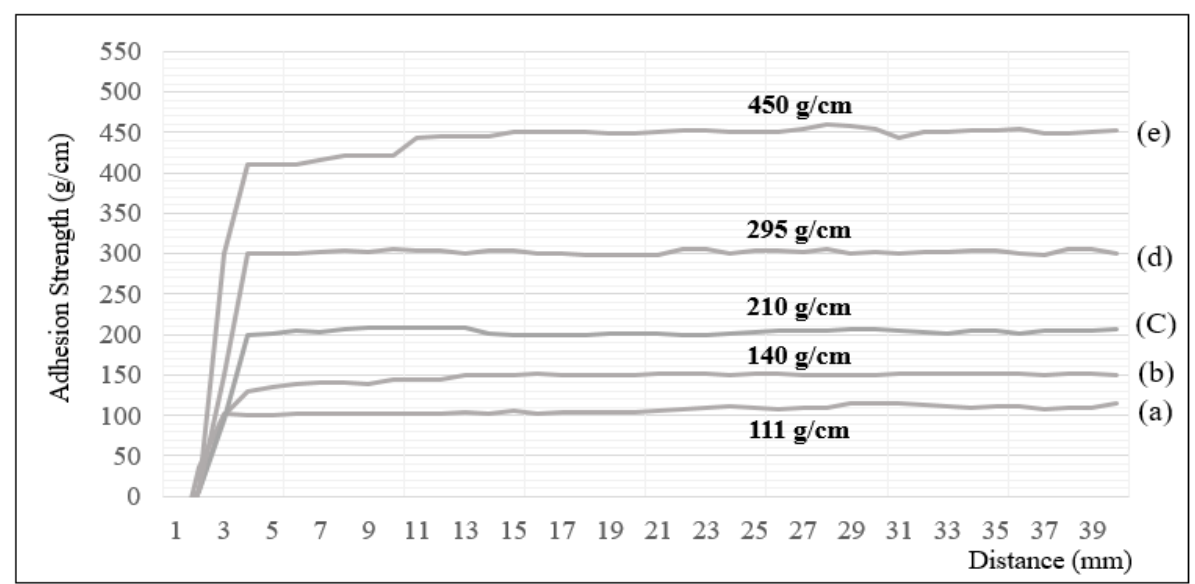

Fig. 2 Results of adhesive strength: (a) untreated, (b) untreated+(*), (c) $150{ }^{\circ} \mathrm{C}-30 \mathrm{~min}+(*),(d) 1,000 \mathrm{~V}-200 \mathrm{sec}+(*)$, (e) 1,300 $\mathrm{V}-200 \mathrm{sec}+(*) ;(*) 150{ }^{\circ} \mathrm{C}-60 \mathrm{~min}$ for electrolytic annealing.
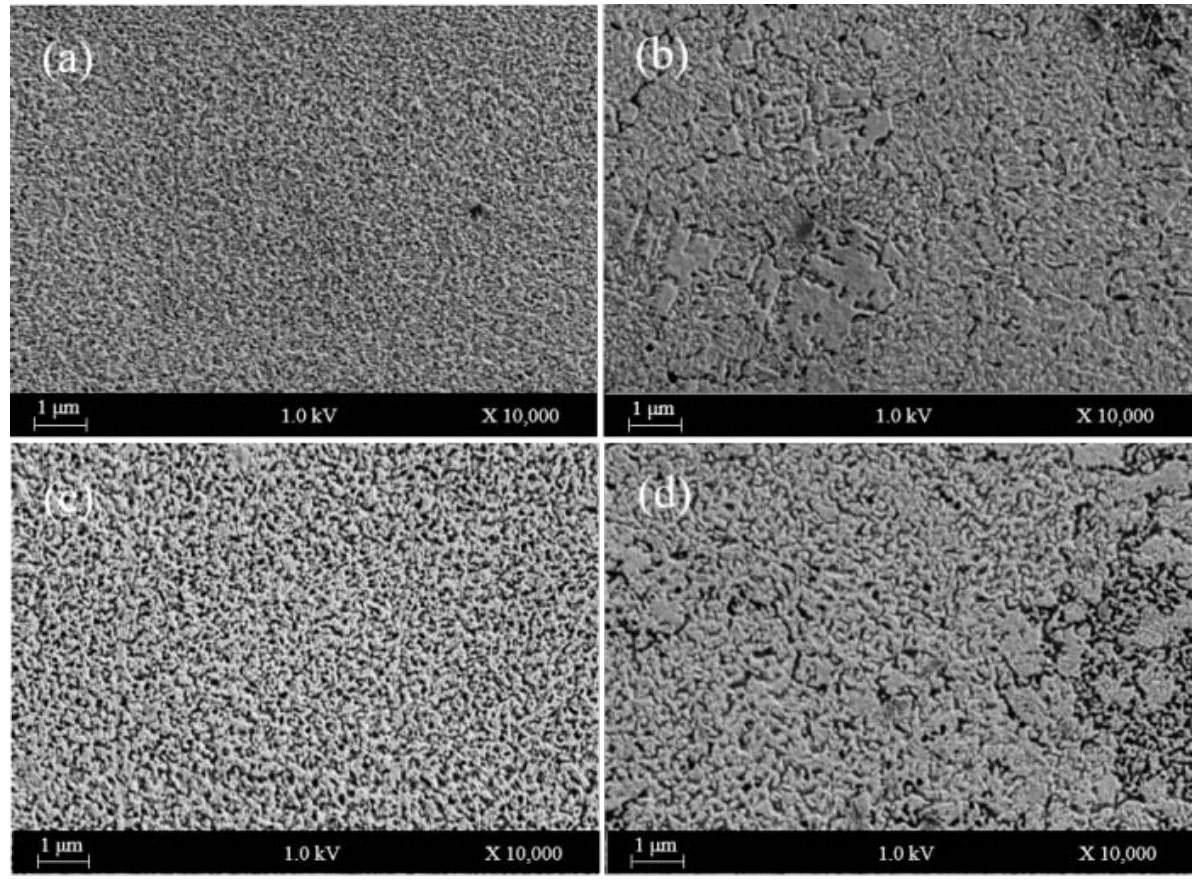

Fig. 3 Observe etched surface by FE-SEM: (a) untreated, (b) $180{ }^{\circ} \mathrm{C}-30 \mathrm{~min}$, (c) 1,000 V-200 sec and (d) 1,300 V-200 sec.

caused in grain boundary diffusion. Furthermore, we expect to improve electromigration as reducing dislocation through growth of $\mathrm{Cu}$ grain size. In the light of $\mathrm{Cu}$ grain size, Figs. 3-5 show results of growth of $\mathrm{Cu}$ grain size. Treated FLA sample shows up almost as same as heat-treated sample. Fig. 6 indicates each treated sample results how much changed slip direction for (111) direction. Although heat treated sample could gain the most improved (111) directions, $1,300 \mathrm{~V}$ to $200 \mathrm{sec}$ sample also was expected relatively to improve slip direction in comparison with other samples.

\subsection{EMC Curing with Small Warpage}

EMC materials used to protect wafer required heat treatment for curing and could expect physical properties like a modulus and tensile strength. Usually EMC material is treated in proximity to $200{ }^{\circ} \mathrm{C}$ to $1 \mathrm{~h}$. We consider that FLA method could be made to reduce warpage issue compared with conventional heat-treatment. Fig. 7 indicates difference of warpage according to each treatment. 

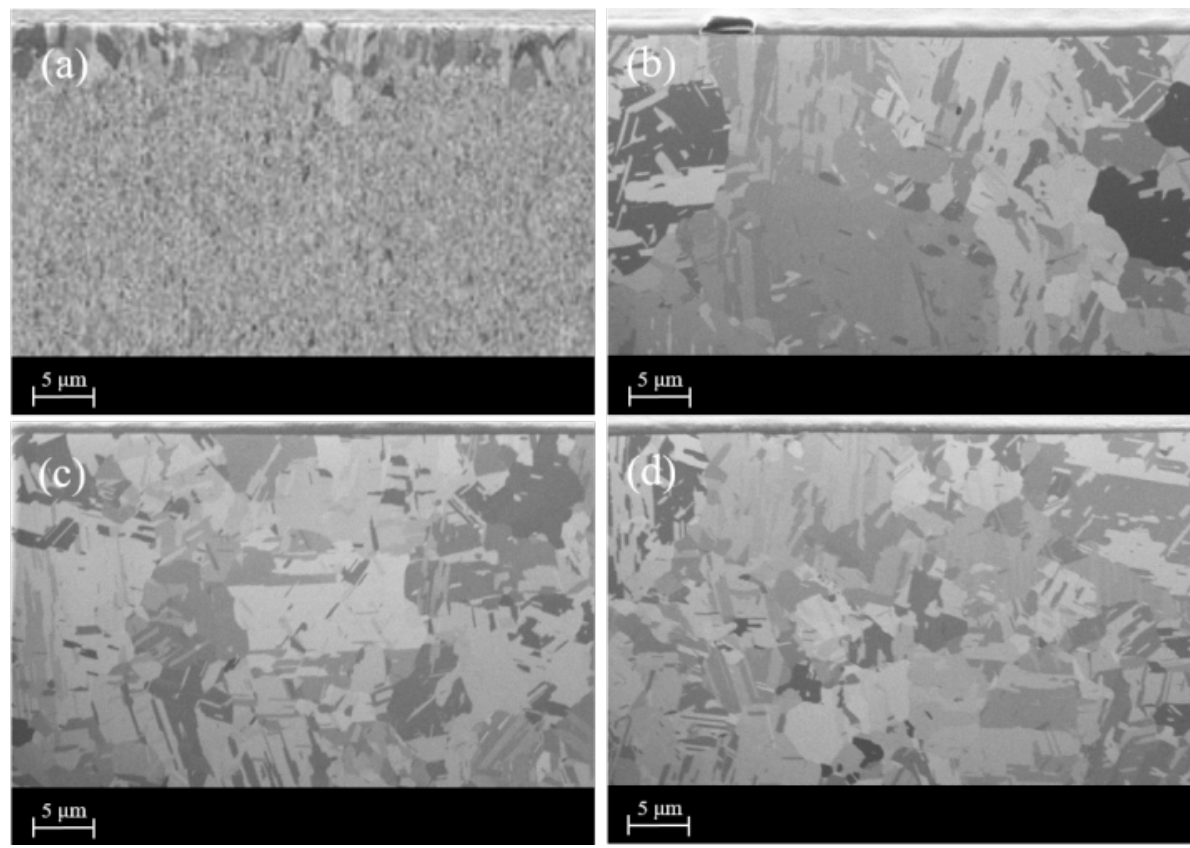

Fig. 4 Results of cross section regarding each treatment by FE-SEM: (a) untreated, (b) $180{ }^{\circ} \mathrm{C}-30 \mathrm{~min}$, (c) $1,000 \mathrm{~V}-200 \mathrm{sec}$ and (d) 1,300 V-200 sec.

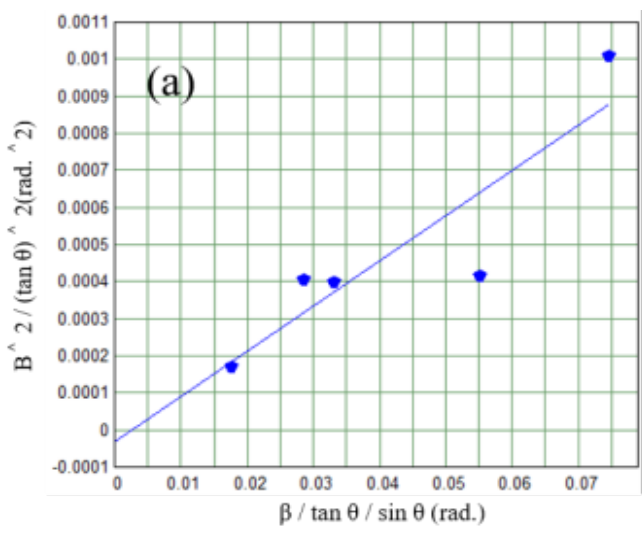

equation : $\mathrm{Y}=0.012 \mathrm{x}-0.00003$

Grain size $(\mathbf{A}): 132$

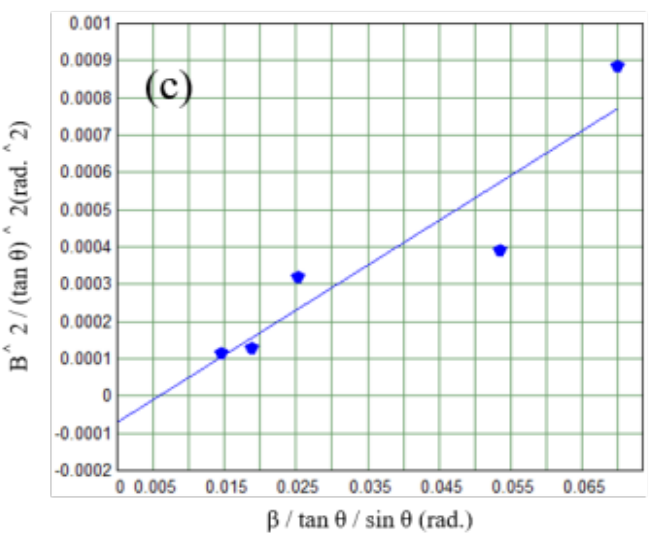

equation : $Y=0.012 x-0.00007$

Grain $\operatorname{size}(\AA)$ : 145

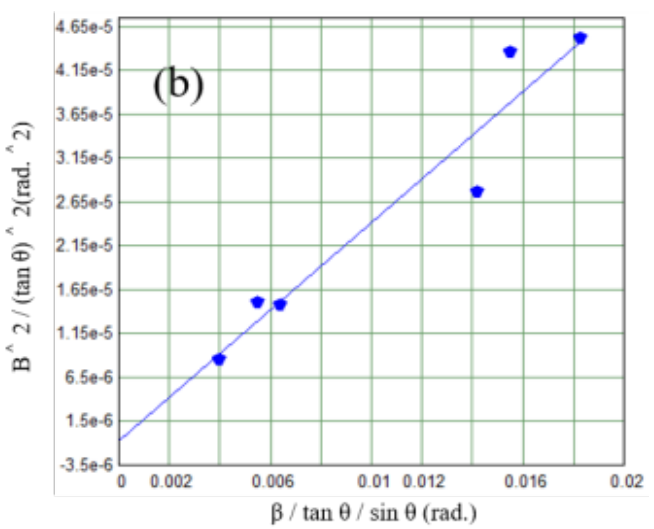

equation : $Y=0.0025 x-0.000001$

Grain size $(\AA)$ : 649

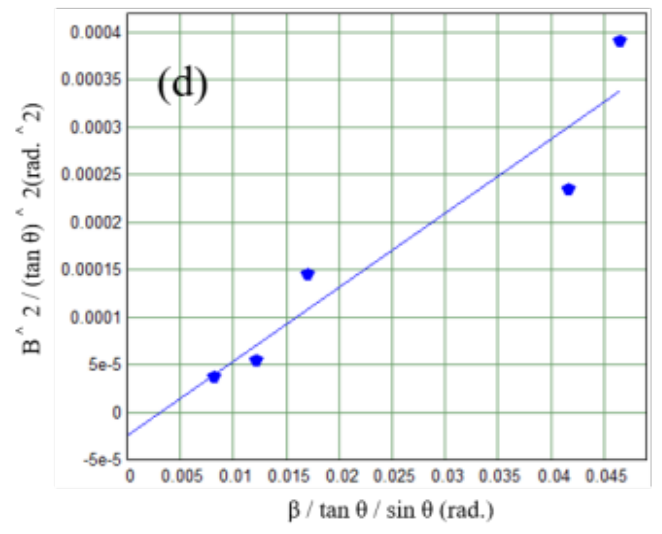

equation : $Y=0.0078 x-0.000002$

Grain size $(\AA)$ : 307

Fig. 5 Grain size of $\mathrm{Cu}$ according to each treatment by XRD: (a) untreated, (b) $180{ }^{\circ} \mathrm{C}-30 \mathrm{~min}$, (c) $1,000 \mathrm{~V}-200 \mathrm{sec}$ and (d) $1,300 \mathrm{~V}-200 \mathrm{sec}$. 

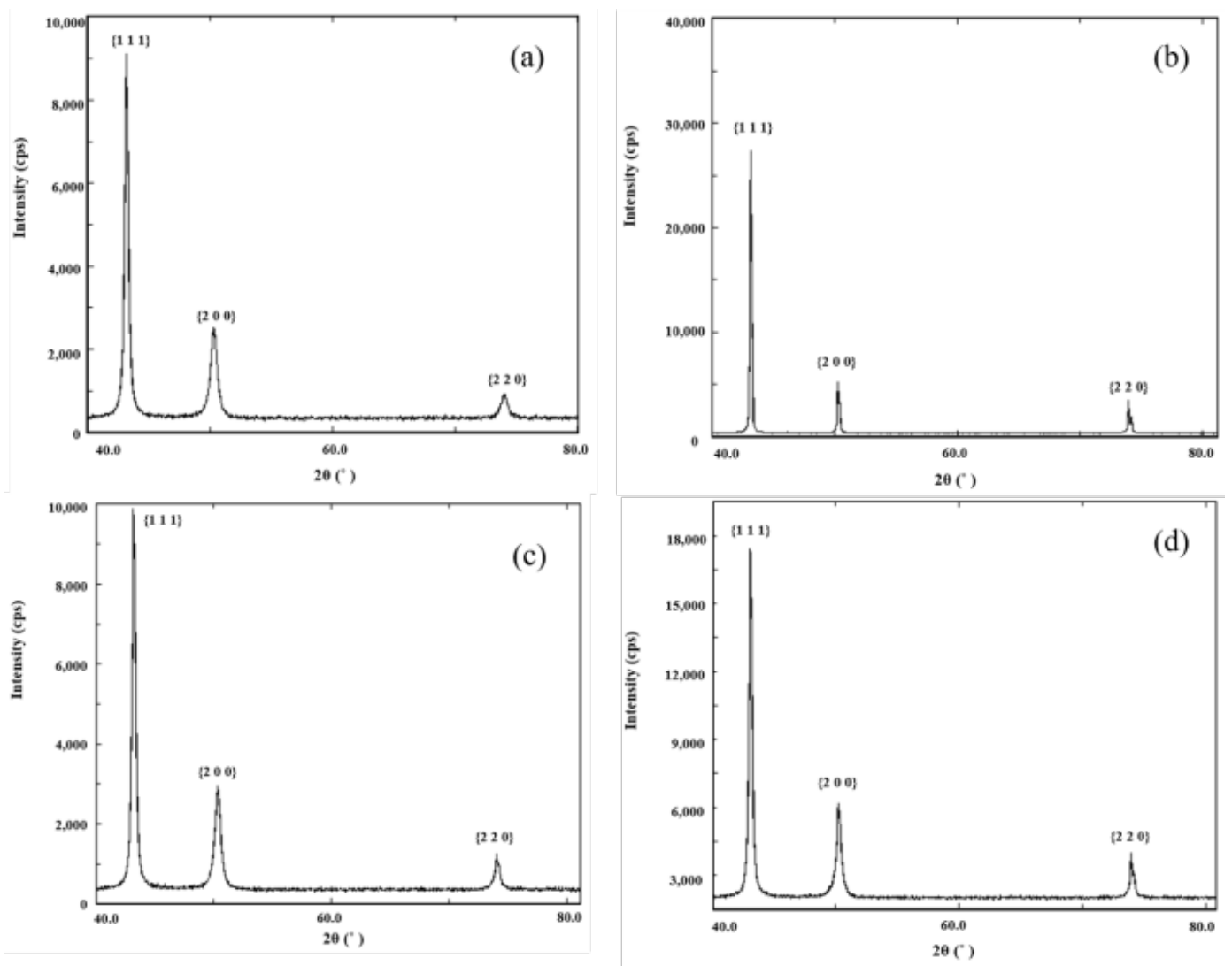

Fig. 6 Results of slip direction by XRD: (a) untreated, (b) $180{ }^{\circ} \mathrm{C}-30 \mathrm{~min}$, (c) 1,000 V-200 sec and (d) 1,300 V-200 sec.
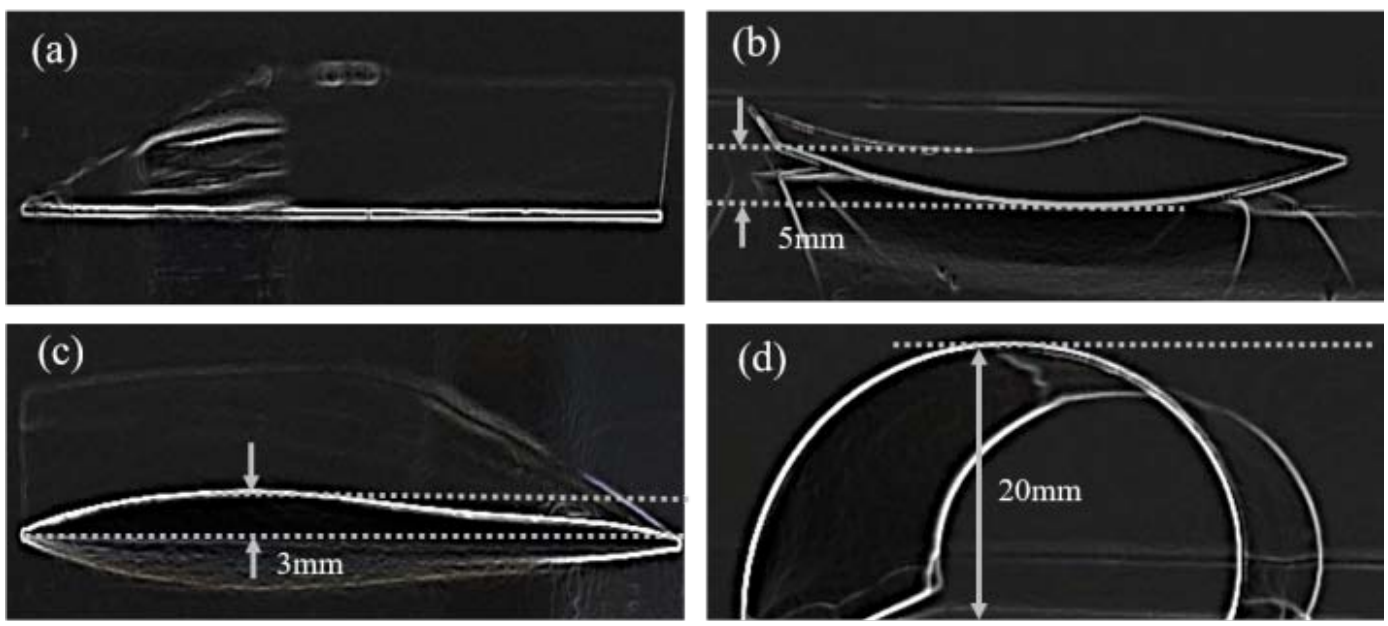

Fig. 7 Results of EMC material warpage after treatment: (a) untreated, (b) $100{ }^{\circ} \mathrm{C}-30 \mathrm{~min}$, (c) $1,300 \mathrm{~V}-200 \mathrm{sec}$ and (d) $180{ }^{\circ} \mathrm{C}-30 \mathrm{~min}$.

Heat treatment with $200{ }^{\circ} \mathrm{C}$ to 60 min occurred at the level of up to $20 \mathrm{~mm}$ warpage but, all FLA treated samples were measured with under $3 \mathrm{~mm}$ warpage. EMC curing is also important that expects physical properties of EMC rough heat treatment. Fig. 8 shows degree of curing by DSC analysis. FLA $1,000 \mathrm{~V}$ to 200 sec and $100{ }^{\circ} \mathrm{C}$ to $30 \mathrm{~min}$ samples showed almost same curing state. In case of sample with FLA $1,300 \mathrm{~V}$ to $200 \mathrm{sec}$ was observed post-cured state. We confirmed it could reduce warpage and curing by FLA treatment. 

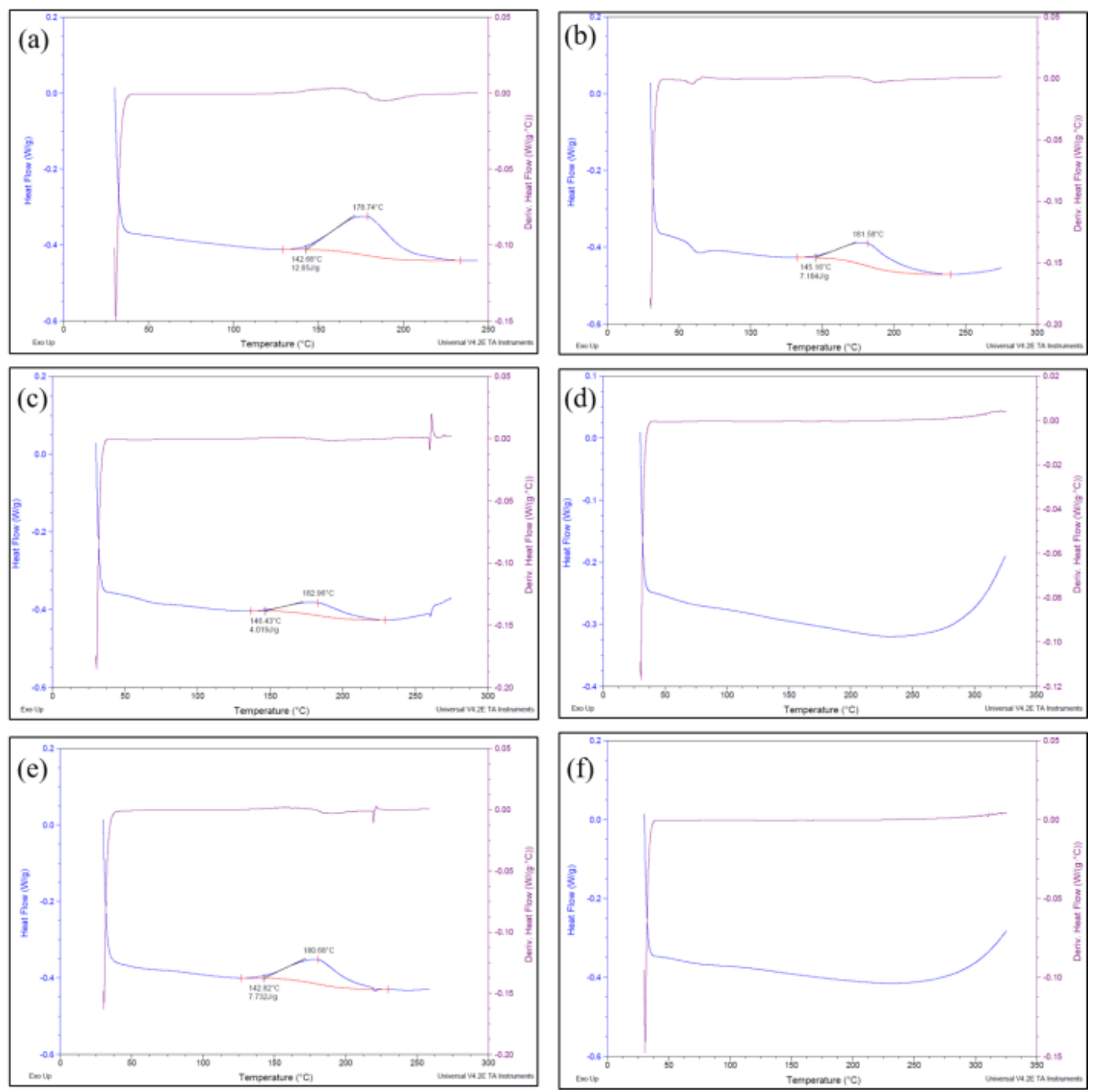

Fig. 8 Results of EMC material degree of curing by DSC: (a) untreated, (b) $100{ }^{\circ} \mathrm{C}-30 \mathrm{~min}$, (c) $120^{\circ} \mathrm{C}-30 \mathrm{~min},(\mathrm{~d}) 180{ }^{\circ} \mathrm{C}-30$ min, (e) 1,000 V-200 sec and (f) 1,300 V-200 sec.

\section{Conclusions}

In this paper, we introduced surface modification on low-loss dielectric and the method of $\mathrm{Cu}$ metallization and EMC curing with reducing warpage for advanced package. We approached improvement of these requirements by FLA treatment. Flash lamp has 200 to $1,000 \mathrm{~nm}$ as pulse wavelength and 0.2 to $1 \mathrm{msec}$ as pulse width, especially lamp can gain higher peak power through pulse width adjusting in the out-put energy. Xe lamp used in FLA has sufficient power for deformation of material; it is because irradiated material has been accumulating power constantly by multi-shot FLA. Adhesive strength between deposited metal and dielectric material can be made to improve which as seed layer diffuses throughout modified layer in dielectric material by FLA treatment. We expect improvement of electromigration through numerous (111) slip direction and growth of $\mathrm{Cu}$ metal including relatively very few dislocations, with FLA treatment not convection or hot plate type heat-treatment. Moreover, FLA can provide EMC curing equal to heat treatment as well as reducing substrate warpage considerably. Therefore, we consider that can make seed layer on the low-loss dielectric material with lower stress and affordable process cost, and improve flip-chip non-wet problem through reducing warpage. 


\section{References}

[1] Lee, I., and Lee, K. C. 2015. "The Internet of Things (IoT): Applications, Investments, and Challenges for Enterprises.” Business Horizons 58: 431.

[2] Kim, Y. J., Park, J. Y., Yoon, K. S., Noh, J. H., Hideo, H., and Osamu, T. 2016. "Improvement of Adhesion by UV Irradiation for the Formation of Cu-Pillar Bumps." Journal of Nanoscience and Nanotechnology 16 (11): 11186-90.

[3] Kim, W., Bae, J. W., Choi, I. D., and Kim, Y. S. 1999. "Thermally Conductive EMC (Epoxy Molding Compound) for Microelectronic Encapsulation.” Polymer Engineering and Science 39 (4): 756-66.

[4] Miyazaki, Y., Suzuki, Y., Horiuchi, Y., Noh, J. H., Honma, H., and Arakawa, T. 2018. "Multishot Flash Lamp Annealing Method for Electroless-Plated Ni-P Film on UV Surface Modified ABS.” Transactions of the IMF 96 (2): 103-7.

[5] Debendra, M., Kaladhar, R., He, J., Chiu, C. P., et al. 2005. "Advanced Package Technologies for High-Performance Systems.” Intel Technology Journal 9 (4): 259-71.

[6] Terai, F., Matunaka, S., Tauchi, A., Ichimura, C., Nagatomo, T., and Homma, T. 2006. "Xenon Flash Lamp Annealing of Poly-Si Thin Films.” J. Electrochem. Soc.
153 (7): 147-50.

[7] Oláh, A., Hillborg, H., and Vancso, G. J. 2005. "Hydrophobic Recovery of UV/Ozone Treated Poly(dimethylsiloxane): Adhesion Studies by Contact Mechanics and Mechanism of Surface Modification.” Applied Surface Science 239 (3-4): 410-23.

[8] Ismail, R. A., Sultan, O. A., and Al-Salam, R. A. 2012. "Xeon Flash Lamp Annealing of Large Area Silicon Photodetector.” J. Nanoelectronics and Materials 5: 31-7.

[9] Ohdaira, K. 2014. "A Method to Evaluate Explosive Crystallization Velocity of Amorphous Silicon Films during Flash Lamp Annealing.” Can. J. Phys. 92: 718-22.

[10] Miura, S., and Honma, H. 2003. "Advanced Copper Electroplating for Application of Electronics.” Surface and Coatings Technology 169-170: 91-5.

[11] Hong, J., Choi, K., Oh, D., et al. 2018. “Design Guideline of 2.5D Package with Emphasis on Warpage Control and Thermal Management.” Presented at IEEE 68th ECTC, San Diego, CA, USA.

[12] LaPedus, M. 2017. “Cheaper Fan-Outs Ahead, Demand for Lower Cost Drives R\&D for Panel-Level Packaging. But Which Size?"

[13] Lee, M., Yoo, M., Cho, J., Lee, S., Kim, J., Lee, C., et al. 2009. "Study of Interconnection Process for Fine Pitch Flip Chip.” Presented at 2009 Electronic Components and Technology Conference, San Diego, CA, USA. 